\title{
Forecasting Large Price Declines of the Nikkei Using the S\&P 500 Implied Volatility
}

\author{
Chikashi Tsuji ${ }^{1}$ \\ ${ }^{1}$ Faculty of Economics, Chuo University, Tokyo, Japan \\ Correspondence: Chikashi Tsuji, Professor, Faculty of Economics, Chuo University, 742-1 Higashinakano, \\ Hachioji-shi, Tokyo 192-0393, Japan. E-mail: mail_sec_low@minos.ocn.ne.jp
}

Received: December 15, 2016

Accepted: December 29, $2016 \quad$ Online Published: January 10, 2017

doi:10.5430/ijba.v8n1p58

URL: http://dx.doi.org/10.5430/ijba.v8n1p58

\begin{abstract}
This paper empirically examines the forecast power of the previous day's US implied volatility for large declines of the Nikkei by using several versions of quantile regression models. All our empirical results suggest that the previous day's US S\&P 500 implied volatility has forecast power for large price drops of the Nikkei 225 in Japan. Since we repeatedly and carefully tested the several left tail risks in price changes of the Nikkei and we also tested by using some different versions of quantile regression models, our evidence of the predictive power of the S\&P 500 implied volatility for downside risk of the Nikkei is very robust.
\end{abstract}

Keywords: downside risk, implied volatility, Nikkei 225, quantile regression model, S\&P 500, tail risk

\section{Introduction}

With globalization of world financial markets as a background, much attention is now being paid to investigations of stock market linkages by academics and practitioners. Globalization of financial markets has different implications for researchers. For example, it has been studied in the context of emerging financial markets and financial instruments (e.g., Riasi, 2015), interdependent financial markets (e.g., Fratzscher, 2002), and financial risk overflows (e.g., Zhu, 2014). However, we point out that many analyses have been conducted for overall market conditions, which include bull, bear, and normal market conditions (e.g., Diebold and Yilmaz, 2009; Baumöhl and Lyócsa, 2014). Differently from the previous studies, in this paper, we thus newly analyze the international stock market linkages by focusing on the downward market condition.

From this new viewpoint, this paper empirically examines the forecast power of the previous day's US S\&P 500 implied volatility for large declines of the Japanese Nikkei 225 stock price index by using several versions of quantile regression models. Our analyses using US and Japanese data supply the following interesting new evidence. First, (1) the estimation results of our simple univariate quantile regression model statistically significantly show that the movement of the previous day's US implied volatility has forecast power for large Nikkei price declines in Japan. Second, (2) the estimation results of our autoregressive (AR)(3)-quantile regression model also statistically significantly suggest that the previous day's US implied volatility has predictive power for large Nikkei declines. Finally, (3) the estimation results of our quantile regression model with additional control variables again statistically significantly evidence that the previous day's US implied volatility has forecast power for large Nikkei price drops in Japan. These new findings from our new analyzing viewpoint are the contributions of this study.

As regards the rest of this paper, Section 2 conducts literature review; Section 3 documents our data and variables we use in this study; Section 4 describes our testing methods; Section 5 provides our results of analyses; and Section 6 presents our interpretations and conclusions.

\section{Literature Review}

This section concisely reviews only recent related studies. Recently, using the data of 32 worldwide emerging and frontier stock markets and the MSCI World stock market index, Baumöhl and Lyócsa (2014) examined the relations between their conditional volatilities and time-varying correlations. Changqing et al. (2015) attempted to measure financial market risk contagion using dynamic Markov Regime Switching Copula (MRS-Copula) models by focusing on Chinese and other international stock markets. Employing a Dynamic Conditional Correlation (DCC) model, Sriananthakumar and Narayan (2015) investigated stock market interdependencies between Sri Lanka and 
USA, Singapore, Malaysia, Pakistan, India, and China.

Further, applying a panel vector autoregressive model to 34 OECD country data, Pradhan et al. (2015) examined their cointegration relations and Granger causality nexuses with regard to economic growth, inflation, and stock market developments. Chuluun (2016) examined global portfolio investment networks and stock market comovements in 49 international countries using network analysis. Boubaker et al. (2016) attempted to assess the contagion between the US stock market and 10 selected developed and emerging equity markets by particularly focusing on the contagion risk that the subprime crisis caused. Moreover, Tsuji (2016) recently rigorously revealed the superior predict power of volatility forecasts from several generalized autoregressive conditional heteroskedasticity (GARCH) models in the US stock market (The journal's web site supplies this paper for free.). However, as far as we know, there is no existing study that analyzed the predict power of US implied volatility for large Japanese stock market declines.

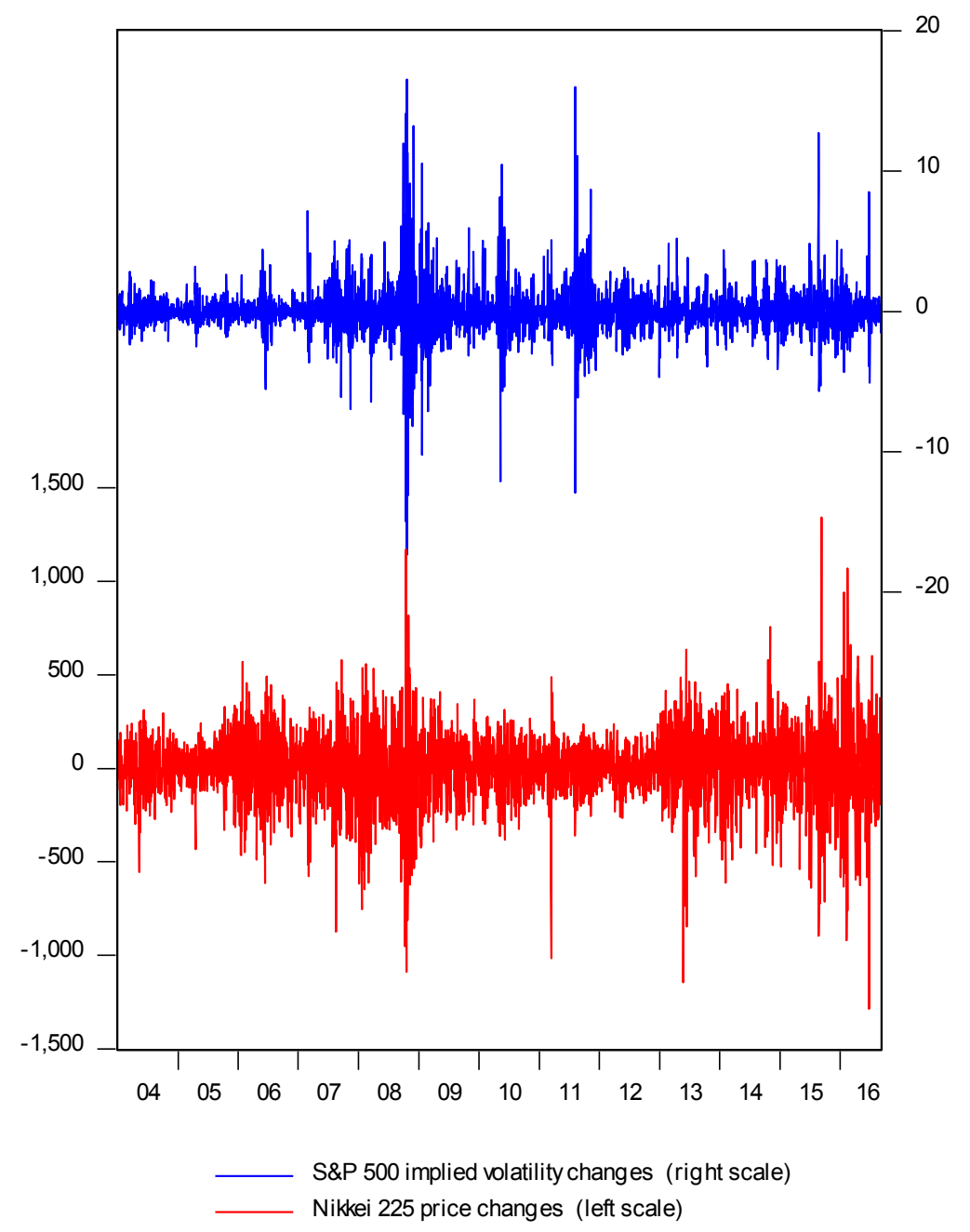

Figure 1. Time-series evolution of the daily changes in the S\&P 500 implied volatility and the Nikkei 225

\section{Data and Variables}

This section describes data and variables for our study. First, DNK denotes the first difference of the Nikkei 225 stock index price in Japan. Second, DSPX means the first difference of the S\&P 500 implied volatility in the US. In addition, we use control variables DTERM and DEX in our tests. Specifically, DTERM denotes the first difference of the yield spread between the Japanese benchmark 10-year government bond yield and the three-month Japanese interbank offered rate; and DEX is the first difference of the Japanese yen exchange rate to the US dollar. 
All samples are daily and the sample period we test in this study spans January 2, 2004 to September 5, 2016. All data used in this study are from Thomson Reuters. Figure 1 displays the time-series of DSPX and DNK for the above sample period. From this figure, we understand that the two series show similar movements for our sample period.

Table 1. Forecast power of the US implied volatility for large Nikkei declines: Results of univariate quantile regressions

\begin{tabular}{|c|c|c|c|c|c|}
\hline \multirow[t]{2}{*}{ Panel A. 6\% left tail } & \multicolumn{5}{|c|}{ Panel B. 5\% left tail } \\
\hline & Coefficient & $p$-value & & Coefficient & $p$-value \\
\hline Const. & $-249.7521 * * *$ & 0.0000 & Const. & $-272.5929 * * *$ & 0.0000 \\
\hline $\operatorname{DSPX}(-1)$ & $-48.4030 * * *$ & 0.0000 & $\operatorname{DSPX}(-1)$ & $-46.8985^{* * *}$ & 0.0000 \\
\hline $\operatorname{Adj} . R^{2}$ & \multicolumn{2}{|c|}{0.094147} & Adj. $R^{2}$ & \multicolumn{2}{|c|}{0.092318} \\
\hline \multirow[t]{2}{*}{ Panel C. 4\% left tail } & \multicolumn{5}{|c|}{ Panel D. 3\% left tail } \\
\hline & Coefficient & $p$-value & & Coefficient & $p$-value \\
\hline Const. & $-297.6566 * * *$ & 0.0000 & Const. & $-350.2519 * * *$ & 0.0000 \\
\hline $\operatorname{DSPX}(-1)$ & $-47.7182 * * *$ & 0.0000 & $\operatorname{DSPX}(-1)$ & $-42.7658 * * *$ & 0.0000 \\
\hline $\operatorname{Adj} . R^{2}$ & \multicolumn{2}{|c|}{0.08879} & Adj.: $R^{2}$ & \multicolumn{2}{|c|}{0.082563} \\
\hline \multirow[t]{2}{*}{ Panel E. 2\% left tail } & \multicolumn{5}{|c|}{ Panel F. 1\% left tail } \\
\hline & Coefficient & $p$-value & & Coefficient & $p$-value \\
\hline Const. & $-425.4153 * * *$ & 0.0000 & Const. & $-511.7494 * * *$ & 0.0000 \\
\hline $\operatorname{DSPX}(-1)$ & $-46.9975 * * *$ & 0.0000 & $\operatorname{DSPX}(-1)$ & $-43.1272 * * *$ & 0.0000 \\
\hline $\operatorname{Adj} . R^{2}$ & \multicolumn{2}{|c|}{0.079022} & $\operatorname{Adj.} R^{2}$ & \multicolumn{2}{|c|}{0.069778} \\
\hline
\end{tabular}

Notes: DSPX(-1) denotes the first lag variable of the first difference of the S\&P 500 implied volatility in the US. Adj. $R^{2}$ means the adjusted $R$-squared value. ${ }^{* * *}$ denotes the statistical significance at the $1 \%$ level.

\section{Testing Methods}

This section explains the testing methods we employ in this study. We use three kinds of quantile regression models to test the predictability of the US implied volatility for large price declines in the Nikkei 225 in Japan. We emphasize that our multiple tests with below three models are effective for robustness checks.

We begin by the following simple univariate quantile regression model (1):

$$
D N K_{t}^{j \%}=\rho_{0}^{j \%}+\rho_{1}^{j \%} \operatorname{DSPX} X_{t-1}+\varepsilon_{t}^{j \%},
$$

where $\mathrm{DNK}^{j \%}$ means the $j$-percentile point of the distribution of the Nikkei 225 price changes and $j$ takes one of the values of $6,5,4,3,2$, and 1 in our analyses (hereinafter the same). Thus, all our model estimations test the forecast power of the US S\&P 500 implied volatility for the downside tail risk in the Nikkei 225 in Japan.

Our next model is the following AR(3)-quantile regression model (2):

$$
D N K_{t}^{j \%}=\eta_{0}^{j \%}+\eta_{1}^{j \%} D \operatorname{SP} X_{t-1}+\sum_{k=1}^{3} \eta_{k+1}^{j \%} D N K_{t-k}+v_{t}^{j \%} .
$$

As shown, the above model includes three AR terms as control variables.

Further, our third test is conducted by the following multiple quantile regression model (3):

$$
\begin{aligned}
D N K_{t}^{j \%}= & \xi_{0}^{j \%}+\xi_{1}^{j \%} D S P X_{t-1}+\xi_{2}^{j \%} D N K_{t-1} \\
& +\xi_{3}^{\xi^{j \%}} D T E R M_{t-1}+\xi_{4}^{j \%} D E X_{t-1}+\tau_{t}^{j \%} .
\end{aligned}
$$

This third model includes the first lags of DNK, DTERM, and DEX as control variables. 
Table 2. Forecast power of the US implied volatility for large Nikkei declines: Results of AR(3)-quantile regressions

\begin{tabular}{|c|c|c|c|c|c|}
\hline \multicolumn{3}{|l|}{ Panel A. 6\% left tail } & \multicolumn{3}{|c|}{ Panel B. 5\% left tail } \\
\hline & Coefficient & $p$-value & & Coefficient & $p$-value \\
\hline Const. & $-250.3194 * * *$ & 0.0000 & Const. & $-276.2992 * * *$ & 0.0000 \\
\hline $\operatorname{DSPX}(-1)$ & $-47.8477 * * *$ & 0.0000 & $\operatorname{DSPX}(-1)$ & $-51.0474 * * *$ & 0.0000 \\
\hline $\operatorname{DNK}(-1)$ & $0.0747 * *$ & 0.0455 & $\operatorname{DNK}(-1)$ & 0.0610 & 0.1052 \\
\hline $\operatorname{DNK}(-2)$ & $0.1349 * * *$ & 0.0016 & $\operatorname{DNK}(-2)$ & $0.1843 * * *$ & 0.0000 \\
\hline $\operatorname{DNK}(-3)$ & $0.1541 * * *$ & 0.0000 & $\operatorname{DNK}(-3)$ & $0.1684 * * *$ & 0.0000 \\
\hline $\operatorname{Adj} . R^{2}$ & \multicolumn{2}{|c|}{0.108571} & $\operatorname{Adj.} R^{2}$ & \multicolumn{2}{|c|}{0.110616} \\
\hline \multicolumn{3}{|l|}{ Panel C. $4 \%$ left tail } & \multicolumn{3}{|c|}{ Panel D. 3\% left tail } \\
\hline & Coefficient & $p$-value & & Coefficient & $p$-value \\
\hline Const. & $-304.2882 * * *$ & 0.0000 & Const. & $-337.1443^{* * *}$ & 0.0000 \\
\hline $\operatorname{DSPX}(-1)$ & $-48.1343 * * *$ & 0.0000 & $\operatorname{DSPX}(-1)$ & $-49.1860 * * *$ & 0.0000 \\
\hline $\operatorname{DNK}(-1)$ & 0.0434 & 0.3276 & $\operatorname{DNK}(-1)$ & 0.0001 & 0.9979 \\
\hline $\operatorname{DNK}(-2)$ & $0.1840 * * *$ & 0.0000 & $\operatorname{DNK}(-2)$ & $0.1872 * * *$ & 0.0000 \\
\hline $\operatorname{DNK}(-3)$ & $0.1593 * * *$ & 0.0007 & $\operatorname{DNK}(-3)$ & $0.1901 * * *$ & 0.0000 \\
\hline $\operatorname{Adj} . R^{2}$ & & & $\operatorname{Adj} . R^{2}$ & 0.1 & \\
\hline \multicolumn{3}{|l|}{ Panel E. 2\% left tail } & \multicolumn{3}{|c|}{ Panel F. $1 \%$ left tail } \\
\hline & Coefficient & $p$-value & & Coefficient & $p$-value \\
\hline Const. & $-401.9958 * * *$ & 0.0000 & Const. & $-512.5970 * * *$ & 0.0000 \\
\hline $\operatorname{DSPX}(-1)$ & $-45.6727 * * *$ & 0.0000 & $\operatorname{DSPX}(-1)$ & $-45.8613 * * *$ & 0.0000 \\
\hline $\operatorname{DNK}(-1)$ & 0.0344 & 0.2135 & $\operatorname{DNK}(-1)$ & 0.0282 & 0.8883 \\
\hline $\operatorname{DNK}(-2)$ & $0.1448 * * *$ & 0.0000 & $\operatorname{DNK}(-2)$ & 0.0583 & 0.2791 \\
\hline $\operatorname{DNK}(-3)$ & $0.1240 * *$ & 0.0297 & $\operatorname{DNK}(-3)$ & 0.0585 & 0.7316 \\
\hline $\operatorname{Adj} . R^{2}$ & \multicolumn{2}{|c|}{0.098527} & $\operatorname{Adj} . R^{2}$ & \multicolumn{2}{|c|}{0.074453} \\
\hline
\end{tabular}

Notes: DSPX(-1) denotes the first lag variable of the first difference of the S\&P 500 implied volatility in the US. DNK $(-k)$ denotes the $k$ th lag variable of the first difference of the Nikkei 225 stock index price in Japan. Adj. $R^{2}$ means the adjusted $R$-squared value. $* * *(* *)$ denotes the statistical significance at the $1 \%(5 \%)$ level.

\section{Results of Analyses}

We first explain the estimation results of the simple univariate quantile regression model (1). Table 1 shows the results. All panels from A to F in Table 1 display that all coefficients of DSPX $(-1)$ are statistically significant at the $1 \%$ level with negative signs. Thus, the results indicate that the previous day's US S\&P 500 implied volatility has forecast power for large Nikkei price declines in Japan.

We next document the estimation results of our second model, the AR(3)-quantile regression model (2). Table 2 displays the results and all panels from A to $\mathrm{F}$ of Table 2 exhibit that again, all coefficients of DSPX $(-1)$ are statistically significant at the $1 \%$ level with negative signs. Hence, the results in Table 2 also suggest that the previous day's US S\&P 500 implied volatility has predictive power for large drops in the Nikkei even if we include three AR variables in our testing model. 
Table 3. Forecast power of the US implied volatility for large Nikkei declines: Results of quantile regressions with control variables

\begin{tabular}{|c|c|c|c|c|c|}
\hline \multicolumn{3}{|l|}{ Panel A. 6\% left tail } & \multicolumn{3}{|c|}{ Panel B. 5\% left tail } \\
\hline & Coefficient & $p$-value & & Coefficient & $p$-value \\
\hline Const. & $-249.6399 * * *$ & 0.0000 & Const. & $-275.7074 * * *$ & 0.0000 \\
\hline $\operatorname{DSPX}(-1)$ & $-48.7715^{* * *}$ & 0.0000 & $\operatorname{DSPX}(-1)$ & $-48.4701 * * *$ & 0.0000 \\
\hline $\operatorname{DNK}(-1)$ & -0.0364 & 0.4812 & $\mathrm{DNK}(-1)$ & -0.0391 & 0.4780 \\
\hline $\operatorname{DTERM}(-1)$ & 89.3092 & 0.7351 & $\operatorname{DTERM}(-1)$ & -54.7192 & 0.8591 \\
\hline $\operatorname{DEX}(-1)$ & 16.8357 & 0.2805 & $\operatorname{DEX}(-1)$ & $26.2650^{*}$ & 0.0608 \\
\hline $\operatorname{Adj} . R^{2}$ & \multicolumn{2}{|c|}{0.094714} & $\operatorname{Adj.} R^{2}$ & \multicolumn{2}{|c|}{0.093845} \\
\hline \multirow[t]{2}{*}{ Panel C. 4\% left tail } & \multicolumn{5}{|c|}{ Panel D. 3\% left tail } \\
\hline & Coefficient & $p$-value & & Coefficient & $p$-value \\
\hline Const. & $-301.0762 * * *$ & 0.0000 & Const. & $-347.6548 * * *$ & 0.0000 \\
\hline $\operatorname{DSPX}(-1)$ & $-47.2295 * * *$ & 0.0000 & $\operatorname{DSPX}(-1)$ & $-45.6444 * * *$ & 0.0000 \\
\hline $\operatorname{DNK}(-1)$ & -0.0130 & 0.8117 & $\operatorname{DNK}(-1)$ & 0.0419 & 0.6292 \\
\hline $\operatorname{DTERM}(-1)$ & -90.1175 & 0.8748 & DTERM $(-1)$ & -1066.5310 & 0.1065 \\
\hline $\operatorname{DEX}(-1)$ & $29.7127^{*}$ & 0.0907 & $\operatorname{DEX}(-1)$ & 29.6416 & 0.1237 \\
\hline $\operatorname{Adj} . R^{2}$ & \multicolumn{2}{|c|}{0.090959} & $\operatorname{Adj} . R^{2}$ & \multicolumn{2}{|c|}{0.085221} \\
\hline \multirow[t]{2}{*}{ Panel E. 2\% left tail } & \multicolumn{5}{|c|}{ Panel F. 1\% left tail } \\
\hline & Coefficient & $p$-value & & Coefficient & $p$-value \\
\hline Const. & $-418.7015^{* * *}$ & 0.0000 & Const. & $-535.0660 * * *$ & 0.0000 \\
\hline $\operatorname{DSPX}(-1)$ & $-44.4865 * * *$ & 0.0000 & $\operatorname{DSPX}(-1)$ & $-37.6213 * * *$ & 0.0000 \\
\hline $\operatorname{DNK}(-1)$ & 0.0465 & 0.6112 & $\operatorname{DNK}(-1)$ & $0.0785^{* * *}$ & 0.0086 \\
\hline DTERM(-1) & -732.0405 & 0.4721 & DTERM $(-1)$ & $-1407.2790 * *$ & 0.0300 \\
\hline $\operatorname{DEX}(-1)$ & 37.6263 & 0.3054 & $\operatorname{DEX}(-1)$ & 21.9822 & 0.5373 \\
\hline $\operatorname{Adj} . R^{2}$ & \multicolumn{2}{|c|}{0.081927} & $\operatorname{Adj} . R^{2}$ & \multicolumn{2}{|c|}{0.078741} \\
\hline
\end{tabular}

Notes: DSPX $(-1)$ denotes the first lag variable of the first difference of the S\&P 500 implied volatility in the US. In addition, DNK $(-k)$ denotes the $k$ th lag variable of the first difference of the Nikkei 225 stock index price in Japan. Moreover, DTERM(-1) denotes the first lag variable of the first difference of the Japanese term spread and DEX $(-1)$ represents the first lag variable of the first difference of the Japanese yen exchange rate to the US dollar. Further, Adj. $R^{2}$ means the adjusted $R$-squared value. ${ }^{* * *}, * *$, and $*$ denote the statistical significance at the $1 \%, 5 \%$, and $10 \%$ levels, respectively.

Finally, we explain the estimation results of our final quantile regression model (3), which includes the control variables of DNK(-1), DTERM $(-1)$, and DEX $(-1)$. Table 3 presents the results and again, all panels from A to $\mathrm{F}$ of Table 3 show that all coefficients of $\operatorname{DSPX}(-1)$ are statistically significant at the $1 \%$ level with negative signs. Therefore, the results in Table 3 again suggest that the previous day's US implied volatility has forecast power for large Nikkei declines even though different control variables are included in our testing model.

As above, we examined six left tail risks of one to six percent downside risks in the distribution of the Nikkei 225 price changes by using three versions of quantile regression models (1) to (3). All results evidenced that the previous day's US S\&P 500 implied volatility has forecast power for large Nikkei price declines in Japan. 


\section{Interpretations and Conclusions}

This paper empirically examined the forecast power of the previous day's US implied volatility for large Nikkei declines by using three kinds of quantile regression models. Our analyses using US and Japanese data revealed the following interesting new evidence. First, (1) the estimation results of our simple univariate quantile regression model statistically significantly revealed that the movement of the previous day's US implied volatility has forecast power for large Nikkei price declines in Japan. Second, (2) the estimation results of our AR(3)-quantile regression model also statistically significantly clarified that the previous day's US implied volatility has predictive power for large Nikkei declines. Finally, (3) the estimation results of our quantile regression model with additional control variables again statistically significantly evidenced that the previous day's US implied volatility has forecast power for large Nikkei price drops in Japan. Differently from previous studies, these new findings from our new analyzing viewpoint — international stock market linkages by focusing on the downward equity market condition — are the most important contributions of this study.

As we described above, all our results evidenced that the previous day's US S\&P 500 implied volatility has forecast power for large price declines of the Nikkei 225 in Japan. Since (1) we repeatedly tested several tail risks of one to six percent left tails in price changes of the Nikkei and (2) we also tested by using three different quantile regression models, it can be naturally emphasized that our results are empirically robust.

In addition, our results can be interpreted that (1) downside risks in US and Japanese stock markets are interdependent (commove) and that (2) there are spillovers (overflows) of downside risks from the US stock market to the Japanese stock market. We emphasize that these are rather new and interesting viewpoints for analyzing and considering international stock market linkages. We note that the findings from this study are useful for future research. Advanced research based on the findings from this study is one of our future tasks. We also consider that the evidence derived from this study is also important for financial risk management and asset management in practice. For instance, practitioners like fund managers and corporate executives should engage in their asset management and financial risk management with the knowledge of the evidence from this study.

\section{Acknowledgements}

The author is particularly grateful to the kind invitation from the journal to write to this journal. I also appreciate the Japan Society for the Promotion of Science Grant-in-Aid for Scientific Research for their generous financial assistance to this research. Moreover, I thank anonymous referees for their highly constructive and supportive comments on this paper. Furthermore, I also thank Jenney Zhang for her skillful editorial assistance to my paper. Finally, I deeply thank all the Editors of this journal for their kind attention on my paper.

\section{References}

Baumöhl, E., \& Lyócsa, Š. (2014). Volatility and dynamic conditional correlations of worldwide emerging and frontier markets. Economic Modelling, 38, 175-183. http://dx.doi.org/10.1016/j.econmod.2013.12.022

Boubaker, S., Jouini, J., \& Lahiani, A. (2016). Financial contagion between the US and selected developed and emerging countries: The case of the subprime crisis. The Quarterly Review of Economics and Finance, 61, 14-28. http://dx.doi.org/10.1016/j.qref.2015.11.001

Changqing, L., Chi, X., Cong, Y., \& Yan, X. (2015). Measuring financial market risk contagion using dynamic MRS-Copula models: The case of Chinese and other international stock markets. Economic Modelling, 51, 657-671. http://dx.doi.org/10.1016/j.econmod.2015.09.021

Chuluun, T. (2016). Global portfolio investment network and stock market comovement. Global Finance Journal, forthcoming. http://dx.doi.org/10.1016/j.gfj.2016.08.002

Diebold, F. X., \& Yilmaz, K. (2009). Measuring financial asset return and volatility spillovers, with application to global equity markets. The Economic Journal, 119, $158-171$. http://dx.doi.org/10.1111/j.1468-0297.2008.02208.x

Fratzscher, M. (2002). Financial market integration in Europe: on the effects of EMU on stock markets. International Journal of Finance \& Economics, 7(3), 165-193. http://dx.doi.org/10.1002/ijfe.187

Pradhan, R.P., Arvin, M.B., \& Bahmani, S. (2015). Causal nexus between economic growth, inflation, and stock market development: The case of OECD countries. Global Finance Journal, 27, 98-111. http://dx.doi.org/10.1016/j.gfj.2015.04.006

Riasi, A. (2015). Competitive advantages of shadow banking industry: An analysis using Porter diamond model. 
Business Management and Strategy, 6(2), 15-27. http://dx.doi.org/10.5296/bms.v6i2.8334

Sriananthakumar, S., \& Narayan, S. (2015). Are prolonged conflict and tension deterrents for stock market integration? The case of Sri Lanka. International Review of Economics and Finance, 39, 504-520. http://dx.doi.org/10.1016/j.iref.2015.08.001

Tsuji, C. (2016). Does the fear gauge predict downside risk more accurately than econometric models? Evidence from the US stock market. Cogent Economics \& Finance, 4: 1220711, 1-42. http://dx.doi.org/10.1080/23322039.2016.1220711

Zhu, H. H. (2014). Financial market risk overflow modeling and inspection based on support vector machine. $\begin{array}{lllll}\text { Applied Mechanics } & \text { Materials, } & \text { 571-572, } & \text { 1189-1194. }\end{array}$ http://dx.doi.org/10.4028/www.scientific.net/AMM.571-572.1189 